\title{
Prognostic Significance of Serum Uric Acid Concentration in Acute Myocardial Infarction
}

\author{
Purna Chandra Karua ${ }^{1}$, Prafulla Kumar Bariha², Sunesh E.R. ${ }^{3}$ \\ 1,2,3 Department of General Medicine, Veer Surendra Sai Institute of \\ Medical Sciences and Research (VIMSAR), Burla, Odisha, India.
}

\section{ABSTRACT}

\section{BACKGROUND}

Acute myocardial infarction is a form of ischemic heart disease in which there is an inadequate supply of blood and oxygen to a portion of the myocardium. It typically occurs when there is an imbalance between myocardial oxygen supply \& demand. In this study, we wanted to determine the prognostic significance of serum uric acid concentration in acute myocardial infarction.

\section{METHODS}

This is a cross-sectional comparative study conducted among 100 acute myocardial infarction patients admitted at VIMSAR, Burla during the study period from November 2017 to October 2019 and also 50 age and gender-matched healthy controls person who presented to the hospital OPD with other reasons. All patients were diagnosed with ST-segment elevation acute myocardial infarction based on clinical history, examination, ECG changes, and biochemical markers. Detailed general examination and detailed systemic examination of cardiovascular, neuromuscular, gastrointestinal, respiratory \& genitourinary system were done with routine tests: Hb\%, TLC, DC, ESR, S. Urea, S. Creatinine, Fasting/RBS, Blood Sugar, Urine, R/M, Serum uric acid, Troponin I \& CPK-MB and ECG in all leads. Evaluation of patient was done to access the Killip class on the day of admission and once among 50 age and gender-matched healthy controls.

\section{RESULTS}

The mean serum uric acid level was higher in patients with acute myocardial infarction than the healthy controls. There was no significant difference in the mean serum uric acid level between males \& females and the mean serum uric acid level between diabetic \& non-diabetic patients. Patients in the higher Killip class had higher serum uric acid levels. All patients who died in the study were in the higher Killip class and had higher S.uric acid levels.

\section{CONCLUSIONS}

A combination of Killip class \& serum uric acid level after acute myocardial infarction is a good predictor of mortality.

\section{KEY WORDS}

Myocardial Infarction, ST Segment Elevation, CPK-MB, Serum Uric Acid.
Corresponding Author: Dr. Prafulla Kumar Bariha, Qr. No. 3R/17, Doctor's Colony, P.0-Burla, Sambalpur-768017, Odisha, India.

E-mail: drpkbariha@gmail.com

DOI: $10.14260 /$ jemds/2022/17

How to Cite This Article:

Karua PC, Bariha PK, Sunesh ER. Prognostic significance of serum uric acid concentration in acute myocardial infarction. J Evolution Med Dent Sci 2022;11(01):88-92, DOI: $10.14260 /$ jemds/2022/17

Submission 29-08-2020,

Peer Review 12-09-2020,

Acceptance 17-01-2022,

Published 25-01-2022.

Copyright (C) 2022 Purna Chandra Karua et al. This is an open access article distributed under Creative Commons Attribution License [Attribution 4.0 International (CC BY 4.0)] 


\section{BACKGROUND}

The term acute myocardial infarction recognizes the clinical continuum resulting from rupture of unstable coronary plaque, with subsequent overlying thrombus formation and blood flow restriction resulting in cardiac chest pain; typical ECG changes or elevation of serum cardiac biomarkers (American journal of medicine, 2002). The most common cause of myocardial ischemia is atherosclerosis of epicardial coronary arteries, sufficient to cause a regional reduction in myocardial blood flow \& inadequate perfusion of the myocardium supplied by the involved coronary artery.

Acute myocardial infarction causes more deaths and disabilities and incurs greater economic costs than any other illness in the developed world. Following myocardial infarction, some proteins and enzymes labelled as cardiac markers (CPK-MB, troponin-t \& I) are released into the blood in large quantities from the necrotic heart muscle. These markers viz. CPK - MB, troponin-t, troponin-I and myoglobin have a specific temporal profile in relation to MI; however, they do not correlate with myocardial function. Epidemiological studies have recently shown that serum uric acid may be a risk factor for cardiovascular diseases and a negative prognostic marker for mortality in subjects with pre-existing heart failure. Elevated serum uric acid is highly predictive of mortality in patients with heart failure or coronary artery disease and cardiovascular events.

Raised serum uric acid concentrations are a powerful predictor of cardiovascular risk and poor outcome, although the underlying mechanisms remain unclear. Several potential explanations have been put forward to explain the apparent association between hyperuricemia and cardiovascular risk. Studies have demonstrated mechanisms by which serum uric acid could be directly injurious to the endothelium and cardiovascular function. Paradoxically, serum uric acid elevation could be expected to confer protective antioxidant effects in the cardiovascular system, but these potential benefits may be obscured by detrimental effects elsewhere.

The effects of raising or lowering serum uric acid on endothelial function, autonomic regulation and progression of atherosclerosis require direct investigation, to understand a possible dual action in the cardiovascular system. Identifying the mechanisms by which serum uric acid interacts with cardiovascular regulation will give us a greater understanding of the role of hyperuricemia for individual patients and allow a more rational approach to treatments that modify serum uric acid concentration.

\section{Objective}

In this study, we wanted to determine the prognostic significance of serum uric acid concentration in acute myocardial infarction.

\section{METHODS}

This is a cross-sectional comparative study conducted among 100 patients with chest pain suggestive of ACS i.e. unstable angina or $\mathrm{Ml}$ within $24 \mathrm{hrs}$ of the onset of symptoms to the OPD of Medicine and Cardiology of VIMSAR, Burla from
November 2017 to October 2019 and also 50 age and gendermatched healthy controls person who presented to the hospital OPD with other reasons.

After obtaining written informed consent, all patients were subjected to detailed history taking, detailed general examination, systemic examination of cardiovascular, neuromuscular, gastrointestinal, respiratory \& genitourinary system, ECG in all leads and blood investigations viz., $\mathrm{Hb} \%$, TLC, DC, ESR, S. Urea, S. Creatinine, Fasting/RBS, urine, serum uric acid and biochemical markers like troponin I \& CPK-MB. Evaluation of the patient was done using Killip classification on the day of admission $\mathrm{D}_{0}, \mathrm{D}_{3}, \mathrm{D}_{7}$.

Clinical criteria for diagnosis of unstable angina are defined as angina pectoris or equivalent ischemic discomfort with at least one of the 3 features, (i) It occurs at rest (or with minimal exertion) usually lasting $>10$ minutes. (ii) It is severe and of new-onset (i.e., within the prior 4-6 wks.), and/or (iii) it occurs with a crescendo pattern (i.e. distinctly more severe, prolonged, or frequent than previous) (iv) postmyocardial infarction angina.

Typical stable angina pectoris is defined as a retrosternal chest discomfort usually described as heaviness, pressure, squeezing, smothering, or choking and only rarely frank pain, lasting 2-5 minutes \& may radiate to the left shoulder and both arms especially to the ulnar surface of forearm \& hand. It may also arise in or radiate to the back, interscapular region, the root of neck, jaw, teeth or epigastrium, which is typically relieved by rest in 1-5 minutes or even more rapidly by sublingual nitroglycerine $\&$ rest. The pain of myocardial infarction is of similar character but is more severe \& lasts longer than 30 minutes $\&$ is not relieved by rest or sublingual nitroglycerine. In cases where the pain is not a prominent feature, other symptoms like profuse sweating, sudden onset dyspnoea, syncope, sudden onset pulmonary oedema in the absence of other known causes of acute left ventricular failure and features of shock characterized by cold clammy skin \& persistent low systolic BP $(\leq 90 \mathrm{~mm} \mathrm{Hg})$ are taken into consideration for diagnosis of AMI. In a person with several known coronary risk factors, when any of these features are present, the possibility of ACS is strongly suspected and the investigations and management are carried out. Patients were evaluated on the day of admission, $3^{\text {rd }}$ day $\& 7^{\text {th }}$ day to find out the Killip class.

In the present study, CK-MB assay was done using Vitro CK-MB DI Slides (Johnson \& Johnson Clinical Diagnostics, Inc, New York). It is a dry multi-layered film that contains all the reagents necessary to determine CK-MB activity in serum. The assay uses anti-human CK-MB antibodies, which inhibit CK-MB (muscle activity). The remaining CK-activity which is proportional to the CK-MB activity catalysed the formation of ATP from creatine phosphate and ADP. The change in reflection density was monitored at $37^{\circ} \mathrm{C}$ and the rate change was then used to calculate enzyme activity. $10 \mu \mathrm{l}$ of serum was used for the assay.

CK-MB results were considered positive as per the following (Kwong T.C.: Studies conducted at the University of Rochester Medical Centre, New York, 1986). S. uric acid was measured on the day of admission and also once among 50 age and gender-matched healthy controls.

Ethical clearance was obtained from the Institutional ethical committee. 


\section{Statistical Analysis}

Basal serum uric acid levels were compared with controls with an unpaired t-test. The levels of S. uric acid were compared using the unpaired t-test. Serum Uric acid levels \& Killip class were compared with Karl Pearson's coefficient of correlation. A probability (P) of less than 0.05 was considered significant.

\section{RESULTS}

The present study was conducted on 100 patients with acute myocardial infarction. Fifty age and sex-matched healthy controls were also evaluated for comparison of uric acid levels.

\begin{tabular}{|c|c|c|c|}
\hline & Study Group & Comparative Group & P-Value \\
\hline Age in years (Mean $\pm S D)$ & $60.28 \pm 10.86$ & $57.36 \pm 5.93$ & \\
\hline Gender & $\mathrm{n}(\%)$ & n (\%) & \\
\hline Males & & & \\
\hline Females & & & \\
\hline
\end{tabular}

\begin{tabular}{|ccccc|}
\hline Group & Number & Mean Age & Std. Deviation & Std. Error of Mean \\
\hline Cases & 100 & 60.28 & 10.863 & 1.086 \\
Controls & 50 & 57.36 & 5.927 & 0.838 \\
\hline \multicolumn{4}{|r|}{ Table $\mathbf{1 b}$. Comparison of Age between Cases and Controls } \\
\hline
\end{tabular}

\begin{tabular}{|ccccc|}
\hline $\begin{array}{c}\text { Serum Uric acid } \\
\text { levels in } \mathrm{mg} / \mathrm{dL} \\
\text { on admission } \\
\text { (Mean } \pm \text { SD) }\end{array}$ & Study Group & $\begin{array}{c}\text { Comparative } \\
\text { Group }\end{array}$ & $\begin{array}{c}\text { t-value } \\
{[95 \% \mathrm{CI}]}\end{array}$ & P-Value \\
\hline Table 2a. Comparison of Serum Uric Acid Levels between Study and \\
Control Groups \\
\hline \multicolumn{5}{|c}{ to -1.10$]$}
\end{tabular}

\begin{tabular}{|ccccc|}
\hline Group & Number & Mean & Std. Deviation & Std. Error of Mean \\
\hline Cases & 100 & 5.1857 & 1.67474 & 0.16747 \\
Control & 50 & 3.6130 & 0.26042 & 0.03683 \\
\hline \multicolumn{4}{|c|}{ Table 2b. Comparison of Serum Uric Acid Level of Cases on Day } \\
o with Controls \\
\hline
\end{tabular}

\begin{tabular}{|c|c|c|c|c|c|c|}
\hline \multirow[t]{2}{*}{$\mathbf{t}$} & \multirow[t]{2}{*}{ df. } & \multirow[t]{2}{*}{$\begin{array}{c}\text { Sig. } \\
\text { (2 Tailed) }\end{array}$} & \multirow[t]{2}{*}{$\begin{array}{c}\text { Mean } \\
\text { Difference }\end{array}$} & \multirow{2}{*}{$\begin{array}{l}\text { Std. Error } \\
\text { of } \\
\text { Difference }\end{array}$} & \multicolumn{2}{|c|}{$\begin{array}{l}95 \% \text { Confidence } \\
\text { Interval of the } \\
\text { Difference }\end{array}$} \\
\hline & & & & & Lower & Upper \\
\hline-6.590 & 148 & 0.00 & -1.57270 & -23866 & -2.04432 & -1.10108 \\
\hline
\end{tabular}

\begin{tabular}{|ccccc|}
\hline Group & Number & $\begin{array}{c}\text { Mean Serum Uric } \\
\text { Acid Level }\end{array}$ & $\begin{array}{c}\text { Std. } \\
\text { Deviation }\end{array}$ & $\begin{array}{c}\text { Std. Error of } \\
\text { Mean }\end{array}$ \\
$\begin{array}{c}\text { Hypertension } \\
\text { No Hypertension }\end{array}$ & 50 & 4.9790 & 1.66058 & .23484 \\
\hline Table 4a. Comparison of Uric Acid Level between Hypertensive \& Non- \\
Hypertensive Patients \\
\hline \multicolumn{5}{|c}{} \\
\hline
\end{tabular}

\begin{tabular}{|ccccc|}
\hline Group & Number & $\begin{array}{c}\text { Mean Serum Uric } \\
\text { Acid Level }\end{array}$ & $\begin{array}{c}\text { Std. } \\
\text { Deviation }\end{array}$ & $\begin{array}{c}\text { Std. Error of } \\
\text { Mean }\end{array}$ \\
Diabetics & 30 & 5.1093 & 1.69325 & .30914 \\
No diabetic & 70 & 5.2184 & 1.67797 & .20056 \\
\hline Table 4b. Comparison of Uric Acid Level on Dayo between Patients with \\
Diabetes and without Diabetes. \\
\hline
\end{tabular}

\begin{tabular}{|ccccccc|}
\hline t & df. & $\begin{array}{c}\text { Sig. } \\
\text { (2 Tailed) }\end{array}$ & $\begin{array}{c}\text { Mean } \\
\text { Difference }\end{array}$ & $\begin{array}{c}\text { Std. Error of } \\
\text { Difference }\end{array}$ & $\begin{array}{c}\text { 95\% Confidence } \\
\text { Interval of the } \\
\text { Difference } \\
\text { Lower }\end{array}$ & Upper \\
-1.355 & 60.270 & .180 & -.46745 & .34495 & -1.15738 & .22249 \\
\hline Table 5. & T-test for Equality of Means for a Uric Acid Level between \\
& Patients with h/o IHD \& without $\boldsymbol{h} / \mathrm{o}$ of IHD \\
\hline
\end{tabular}

\section{DISCUSSION}

Out of 100 patients, 60 had ST-elevation myocardial infarction while 40 patients had non-ST elevation myocardial infarction, 30 patients were thrombolysed while rest were not thrombolysed due to delayed presentation, serum uric acid was treated as a continuous and a categorical variable and variables were divided into quartiles according to same as in referral studies by Kojima et al. ${ }^{1}$ and by My Nadakar \& VJ Jain. ${ }^{2}$

The maximum number of patients was in the age group of 51-60 yrs. contributing $38 \%$ of all cases. In all 67 male and 33 female patients were taken and the male to female ratio was 2.03. A maximum number of controls was in the group of 51-60 yrs. and the male: female ratio was 29:21.

The age between cases and controls, the mean age of cases was $60.28 \mathrm{yrs}$. with a standard deviation of 10.863 . The mean age of control was 57.36 yrs. with a standard deviation of 5.927. The mean serum uric acid level of cases was 5.1857 with a standard deviation of 1.67474, the mean uric acid level of controls was 3.6130 and the standard deviation was. 26042. T-test for equality of means for serum uric acid on day 0 between cases \& controls showed a 2 tailed significance of 0.00 , which means a significant difference in the S.uric acid level between cases on dayo \& healthy controls. In 100 cases, $50 \%$ were hypertensives; $72 \%$ of hypertensives were males and $28 \%$ were females.

The mean serum uric acid level of hypertensives was 4.9790 with a standard deviation of 1.66058 . The mean serum uric acid level of patients without hypertension was 5.3924 with a standard deviation of 1.6799 . In this study, 30 $\%$ of cases had diabetes mellitus, $73 \%$ of diabetic patients were males and $27 \%$ were females. The mean uric acid level of diabetic patients was 5.1093 and the standard deviation was 1.6933. The mean uric acid level of non-diabetics was 5.2184 with a standard deviation of 1.67797 .

The mean serum uric acid level of patients with $\mathrm{H} / \mathrm{O}$ of IHD was 5.5176 with a standard deviation of 1.48973 . The mean serum uric acid level of patients without H/O IHD was 5.0501 with a standard deviation of 1.73631 . The t-test showed a 2 tailed significance of 0.180 , this means that patients' ischemic heart disease history status does not influence the S.uric acid level in acute myocardial infarction.

There was no significant difference between $(\mathrm{P}=0.219)$ serum uric acid levels in patients who were known or found to be hypertensive on admission and patients without hypertension. This is different from other studies which showed that hypertensive patients had more hyperuricemia. (Kojima.s, Sukamoto.t, Ishihara M et al. ${ }^{1}$ Japanese acute coronary syndrome study)

Studies by Johnson R J, Rodriguez-Iturbe B, Kang DH, et al. ${ }^{3}$ also showed that hypertensive patients had more hyperuricemia.

Thirty percent of patients were known diabetics in this study. Non-diabetic and diabetic patients had comparable serum uric acid levels on Day 1. This finding is consistent with a study by Tuomilheto et al. $^{4}$ in which there was no significant association between serum uric acid level and diabetic status. However, this finding is in contrast to other studies by Safi et al. which showed that hyperuricemia was significantly associated with type 2 DM. 
Previous studies have shown that hyperuricemia is often associated with insulin resistance and by extension with metabolic syndrome. ${ }^{5}$

The frequency with which hyperuricemia accompanies insulin resistance has led to the belief that uric acid may be a consequence of hyperinsulinaemia, however, it has also been noted that hyperuricemia predicts subsequent development of diabetes even before there is clinical evidence of renal dysfunction, insulin resistance or impaired glucose tolerance. (Perry J et al.) ${ }^{6}$

There were 29 patients in the present study with a previous history of ischemic heart disease. The mean serum uric acid level on dayo with a history of ischemic heart disease was $5.0501 \pm 1.736$; the mean uric acid level on dayo of those who had no h/o of ischemic heart disease was $5.5176 \pm 1.49$. Two-tailed significance was 0.18 , i.e. there was no significant difference in mean uric acid level between the two groups. Previous studies showed a significant difference between these two groups (Kojima.s, Sukamoto.t, Ishihara M et al. ${ }^{1}$ Japanese acute coronary syndrome study \& My Nadakar and VJ Jain). ${ }^{2}$

Hyperuricemia is very common in patients with heart failure. Several studies notably those by Anker, coats and others demonstrated a very powerful association between serum uric acid and mortality (levya F, Anker S, Swan JW, et al). ${ }^{7}$

Killip classification is an indicator of the severity of heart failure (Harrison's principles of internal medicine $1^{\text {th }}$ Edition). The discriminating capacity of serum uric acid in heart failure is greater than that of such traditional predictors as clinical status, exercise capacity and renal function.

In the present study, the patients were divided into Killip class according to the clinical status \& uric acid level was divided into 4 quartiles. There were 43 patients in the Killip class I, 27 of them were in the first quartile, 15 were in the second quartile \& one was in the fourth quartile. Out of the 24 patients in the Killip class II, 21 of them were in the second quartile \& 3 were in the first quartile. There were 20 patients in the Killip class III, 11 of them in the fourth quartile \& 9 were in the third quartile. All the 13 in the Killip class IV were in the fourth quartile. It shows a positive correlation (Karl Pearson's coefficient of correlation 0.898) between Killip class \& S.uric acid level.

There were 57 patients in the Killip class I on day, 48 of them were in the first quartile, 9 were in the second quartile \& out of the 12 patients in the Killip class II, one was in the first quartile, 10 of them were in the second quartile \& one was in the third quartile. Out of the 5 patients in Killip class III, four were in the third quartile \& one was in the 4 th quartile. There were 26 patients in the Killip class IV of whom 25 of them were in the fourth quartile \& one was in the third quartile. It shows a positive correlation (Karl Pearson's coefficient of correlation 0.968 ) between Killip class \& S.uric acid level.

There were 67 patients in the Killip class I on day7 of whom 57 of them were in the first quartile, 9 were in the second quartile \& one was in the 3rd quartile. One patient in the Killip class II was in the 3rd quartile, out of the 5 patients in Killip class III, four were in the third quartile \& one was in the 4 th quartile. There were 27 patients in the Killip class IV, 26 of them were in the fourth quartile \& one was in the third quartile. It shows a positive correlation (Karl Pearson's coefficient of correlation 0.954 ) between Killip class \& S.uric acid level.

In a study of 294 subjects with chronic heart failure, there were 116 deaths during 10 yrs. of follow up. The 12 subjects with serum uric acid $>13.44 \mathrm{mg} / \mathrm{dl}$ died during the first $3 \mathrm{yrs}$, while $70 \%$ of the 100 subjects with serum uric acid $<6.72$ $\mathrm{mg} / \mathrm{dl}$ were alive at 9 years (Bickel. c, Ruprecht $\mathrm{HJ}$, Blankenberg S et al.) ${ }^{8}$

Previous studies have shown that uric acid level increases in heart failure. There was a correlation between serum uric acid level \& Killip class as in earlier studies (Kojima.s, Sukamoto. t, Ishihara $\mathrm{M}$ et al. ${ }^{1}$ Japanese acute coronary syndrome study \& My Nadakar and VJ Jain). ${ }^{2}$
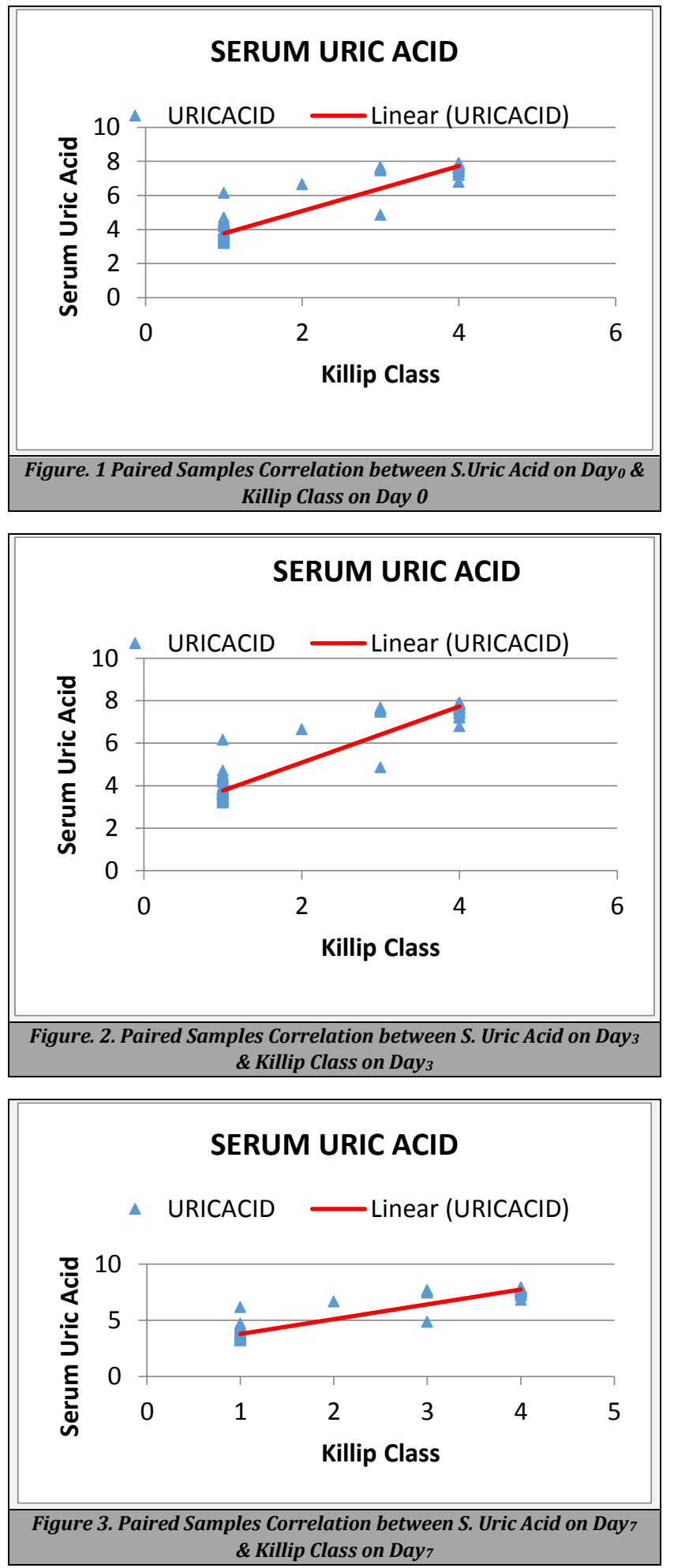
In this study, serum uric acid level correlates with the severity of heart failure. There was a statistically significant positive correlation between serum uric acid level on dayo, days \& day7 \& Killip class on day0, day3 \& day7 (Fig. 1 to 3) $(\mathrm{P}=0.00)$. Patients of Killip class III \& IV had higher levels of uric acid as compared to the patients of Killip class I \& II.

Previous studies have shown that hyperuricemia is a powerful predictor of mortality in persons with angiographically demonstrated coronary atherosclerosis. (Bickel. C, Ruprecht HJ, Blankenberg. S et al.) ${ }^{8}$

Patients with the highest quartile of SUA were 5 times more likely to die during the study than those with the lowest quartile. The relation of serum uric acid to cardiovascular disease outcome was continuous and independent of other risk factors. One $\mathrm{mg} / \mathrm{dl}$ increase in serum uric acid was associated with a $26 \%$ increase in mortality (Bickel. c, Ruprecht HJ, Blankenberg. S et al). ${ }^{8}$

Out of 100 patients, six expired during 7 days follow up. All the patients who died had serum uric acid levels of more than $7 \mathrm{mg} / \mathrm{dl}$. Out of these, one was in Killip class III \& 5 were in Killip class IV at the time of admission. $100 \%$ of patients who died were in higher Killip class, i.e. class III \& IV at the time of admission. All six patients had serum uric acid levels in the fourth quartile on the day of admission. Therefore, it is shown that serum uric acid concentration level is significantly correlated with cardiovascular mortality in patients with acute myocardial infarction.

\section{CONCLUSIONS}

A century of clinical observations and a wealth of knowledge gained in recent decades have propelled acute myocardial infarction to the forefront of clinical practice and research in cardiology. Because of the increasingly high incidence of these acute syndromes and their serious prognoses particularly in developing countries like India, physicians and cardiologists should be more aware regarding early diagnosis and treatment strategies to prevent progression into myocardial damage. Considering the importance of early diagnosis, risk stratification and timely interventions in acute myocardial infarction, this study was undertaken and the following conclusions were drawn.

Serum uric acid level was higher in patients with acute myocardial infarction as compared to normal healthy persons. There was no significant difference in the mean uric acid level between males \& females in the study. Mean uric acid level was not affected by the previous history of ischemic heart disease, diabetic \& hypertensive status of the cases. There was a statistically significant positive correlation between serum uric acid level \& Killip class. A combination of Killip class and S. uric acid levels after acute myocardial infarction is a good predictor of mortality after AMI.

These findings strongly suggest the clinical importance of monitoring and intervention based on increased serum uric acid. However, there is insufficient evidence to justify hypouricemic treatment to prevent cardiovascular mortality, at the same time, no evidence exists that low or reduced uric acid is harmful.

Data sharing statement provided by the authors is available with the full text of this article at jemds.com.

Financial or other competing interests: None.

Disclosure forms provided by the authors are available with the full text of this article at jemds.com.

The authors would like to thank our patients for their adherence and kind cooperation in this study and the staff and technicians for performing the different tests in the study.

\section{REFERENCES}

[1] Kojima S, Sakamoto T, Ishihara M, et al. Prognostic usefulness of serum uric acid after acute myocardial infarction (Japanese Acute Coronary Syndrome Study). Am J Cardiol 2005;96(4):489-95.

[2] Nadkar MY, Jain VI. Serum uric acid in acute myocardial infarction. J Assoc Physicians India 2008;56:759-62.

[3] Johnson RJ, Rodriguez-Iturbe B, Kang DH, et al. A unifying pathway for essential hypertension. Am J Hypertens 2005;18(3):431-40.

[4] Tuomilehto J, Zimmet P, Wolf E. Plasma Uric acid level and its association with diabetes mellitus and some biologic parameters in a biracial population of Fiji. Am J Epidemiol 1988;127(2):321-36.

[5] Tsunoda S, Kamide K, Minami J, et al. Decreases in serum uric by amelioration of insulin resistance in overweight hypertensive patients: effect of a low-energy diet and an insulin sensitizing agent. Am J Hypertension 2002;15(8):697-701.

[6] Perry IJ, Wannanetheee SG, Walker MK, et al. Prospective study of risk factors for development of non-insulin dependent diabetes in middle age British men. BMJ 1995;310(6979):560-4.

[7] Leyva F, Anker S, Swan JW, et al. Serum uric acid as an index of impaired oxidative metabolism in chronic heart failure. Eur Heart J 1997;18(5):858-65.

[8] Bickel C, Rupprecht HJ, Blankenberg S, et al. Serum uric acid as an independent predictor of mortality in patients with angiographically proven coronary artery disease. Am J Cardiol 2002;89(1):12-7. 